$11^{\text {th }}$ International Conference on Modern Research in MANAGEMENT, ECONOMICS and ACCOUNTING 18-20 December, 2020 Oxford, United Kingdom

\title{
Probability quantification model of a banking crisis and CDS`s implications
}

\author{
Adina-Ionela Străchinaru
}

Bucharest University of Economic Studies

\begin{abstract}
The paper is aiming to emphasize the importance of prudential supervisation in order to ensure financial stability in terms of identifying tools, designed to anticipate the influence of macroeconomic indicators, whose history has indicated episodes of economic collapse at international level. Using a logistic regression, I captured a model for quantifying the probability of banking crises, integrating indicators of the scoreboard on macroeconomic imbalances, as well as the sovereign risk premium, expressed by the CDS 5Y rating for European countries. In this sense, the results show the premises underlying the elaboration of the analytical framework for the propagation of sovereign risk at credit institutions level.
\end{abstract}

Keywords: banking crisis, early warning indicators, sovereign risk 